\title{
Nodal histiocytic disorder in children: report of three cases and review of literature
}

\author{
Indumathi Ainer ${ }^{{ }^{*}}$ (D), Hardip Singh Gendeh², Salina Binti Husain² and Khadijah Mohd Nor $^{3}$
}

\begin{abstract}
Background: Histiocytic system consists of phagocytes and dendritic cells. Both are found in lymph nodes. Usually, this disorder presents with painless cervical lymph node enlargement hence frequently mistaken for lymphoma or tuberculosis.

Case presentation: Here, we report three pediatric cases: one of Langerhans cell histiocytosis and two of sinus histiocytosis and massive lymphadenopathy with neck mass as initial presentation. The final diagnosis was made with fine needle aspiration cytology, biopsy, and ancillary tests.
\end{abstract}

Conclusion: Biopsy and immunohistochemistry studies are recommended for determining subtypes of histiocytosis and further management of patient.

Keywords: Histiocytosis, Lymphadenopathy, Histopathology, Children, Langerhans cell, Case report

\section{Key messages}

Histiocytosis disorder in children is rare, and presentation as cervical lymphadenopathy is often mistaken as other pathology. Here, we are reporting three pediatric cases of histiocytosis and its variant.

\section{Background}

Childhood histiocytoses are a rare and diverse group of disorders that can cause generalized lymphadenopathy [1]. The classic presentation is painless massive lymphadenopathy. Although rare, in children it can mimic lymphoproliferative disease. Clinical course can be variable from spontaneous regression to a period of stable lymphadenopathy. It is a challenge to obtain biopsy in children as general anesthesia is almost always indicated. In these cases, imaging such as ultrasound and computed tomography (CT) will uplift the diagnosis.

\footnotetext{
* Correspondence: induainer@hotmail.com

${ }^{1}$ Department of Otorhinolaryngology, UKM Medical Centre, Jalan Yaacob

Latiff, Bandar Tun Razak, 56000 Cheras, Kuala Lumpur, Malaysia

Full list of author information is available at the end of the article
}

Here, we present our experience in managing three pediatric cases with age of 10 months, 11 months, and 3 years old. We describe the clinical manifestations, difference of histopathology features of two subtypes, its immunohistochemistry studies and long-term follow up.

\section{Case presentation \\ Case 1}

A 10-month old boy presented to our clinic with increasing right neck swelling 1 month prior to presentation. He had a co-existing scalp infection with noisy breathing for 1 month and reduced feeding. There was no fever, cough, rhinorrhoea, aspiration symptoms, and loss of weight. Baby was born full term via spontaneous vaginal delivery.

Clinical examination revealed palpable right neck swelling at posterior triangle measuring $5 \times 5 \mathrm{~cm}$, firm, non-tender with erythematous skin. There was eczematous rash over the scalp and neck. Other system review was unremarkable. A complete blood count was taken and showed normal cell counts. Neck ultrasound showed a large irregular collection at

\section{Springer Open}

(c) The Author(s). 2020 Open Access This article is licensed under a Creative Commons Attribution 4.0 International License, which permits use, sharing, adaptation, distribution and reproduction in any medium or format, as long as you give appropriate credit to the original author(s) and the source, provide a link to the Creative Commons licence, and indicate if changes were made. The images or other third party material in this article are included in the article's Creative Commons licence, unless indicated otherwise in a credit line to the material. If material is not included in the article's Creative Commons licence and your intended use is not permitted by statutory regulation or exceeds the permitted use, you will need to obtain permission directly from the copyright holder. To view a copy of this licence, visit http://creativecommons.org/licenses/by/4.0/. 


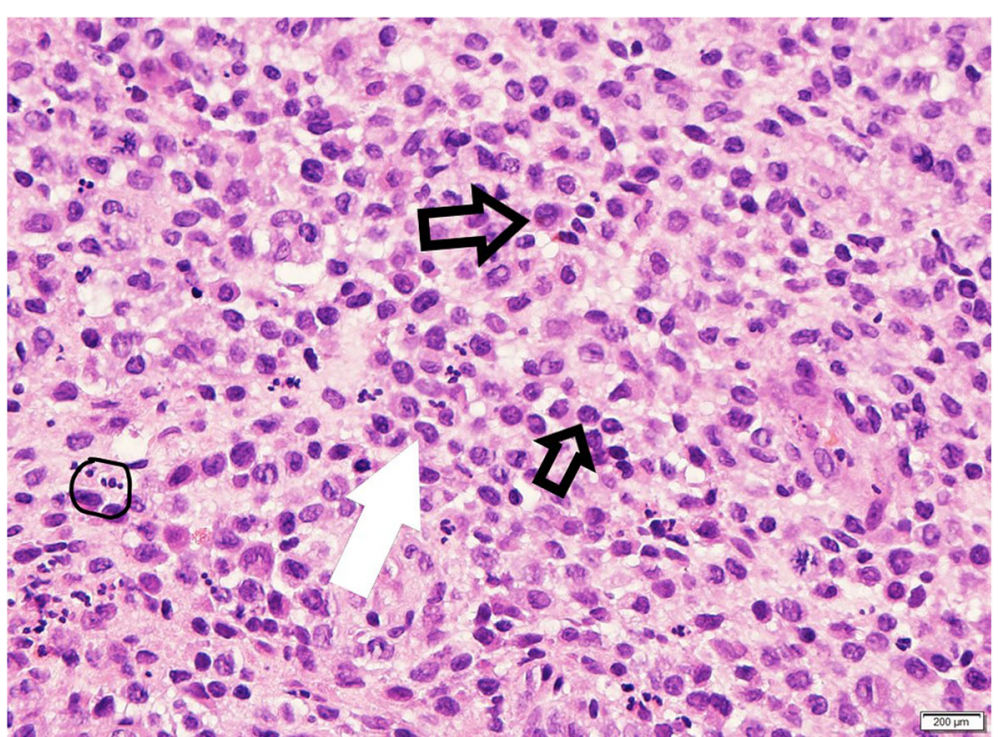

Fig. 1 Microscopic findings: Numerous dyscohesive sheets of neoplastic cells which are moderate in size displaying rather uniform grooved nuclei. (black arrows). Some of the cells show indented and kidney-bean shaped nuclei (white arrow). Mitotic figures are frequent and abnormal forms are present. Scattered mixed population of eosinophils, lymphocytes and some neutrophils (black circle) are also seen in the background. CD1 alpha and S100 are positive

right jugular and posterior region measuring $5.4 \times 2.4$ $\times 1.8 \mathrm{~cm}$ and multiple enlarged cervical lymph nodes with preserved fatty hilum. Biopsy of cervical lymph node revealed Langerhans cell histiocytosis (Fig. 1). Patient was then managed conservatively. His neck swelling is progressively reducing in size upon clinic follow-ups.

\section{Case 2}

An 11-month-old boy, brought by his mother, presented with an acute onset of left neck swelling which began 1 month prior. It was progressively increasing in size and associated with eczema over face and scalp region. There was similar swelling over the submental region. There was no fever and no upper respiratory tract infection. He was active and thriving well. He has underlying afebrile seizure diagnosed at 7 months of life and remains fit free till now.

Examination of the neck showed left neck swelling measuring $3 \times 4 \mathrm{~cm}$ at anterior triangle, firm, nontender with no skin changes. He completed a short course of antimicrobial therapy (Co-amoxiclav). A full blood count performed revealed neutrophilia. Neck ultrasound revealed bilateral cervical lymphadenopathy with largest diameter of $3 \mathrm{~cm}$. An excision biopsy was performed under general anesthesia. Histopathology examination shows monomorphous histiocytes, lymphocytes, and few multinucleated giant cells showing a feature of sinus histiocytosis. Swelling reduced in size after a course of steroids (prednisolone). Neck swelling completely regressed on follow-ups at 3,6 , and 12 months.

\section{Case 3}

A 3-year-old boy presented with right neck swelling for the past 6 months. There was no noisy breathing, fever, pain, loss of weight, and feeding issues. He had two previous admissions for the same complaint and had completed two courses of antibiotics; however, swelling remains the same.

A full blood count performed showed anemia with normal white cell count and platelets. Full blood picture was taken and revealed hypochromic microcytic anemia. Ultrasound shows multiple enlarged nodes noted in the right submandibular, right posterior and anterior cervical triangle, and also in the left submandibular region. Fine needle aspiration (FNA) revealed low cellularity smears with prominent large histiocytes suggestive of reactive lymphadenopathy. Excision biopsy report rendered towards reactive sinus histiocytosis.

The neck swelling increased in size post FNA and occupying most of the anterior triangle without airway compromise. A CT showed multiple cervical, supraclavicular, retropharyngeal, mediastinal, and left hilar lymphadenopathies (Fig. 2 a and b). Prednisolone was administered with clinical improvement. He was seen as outpatient at 6 months intervals (Fig. 3). His neck swelling is smaller compared to before. 

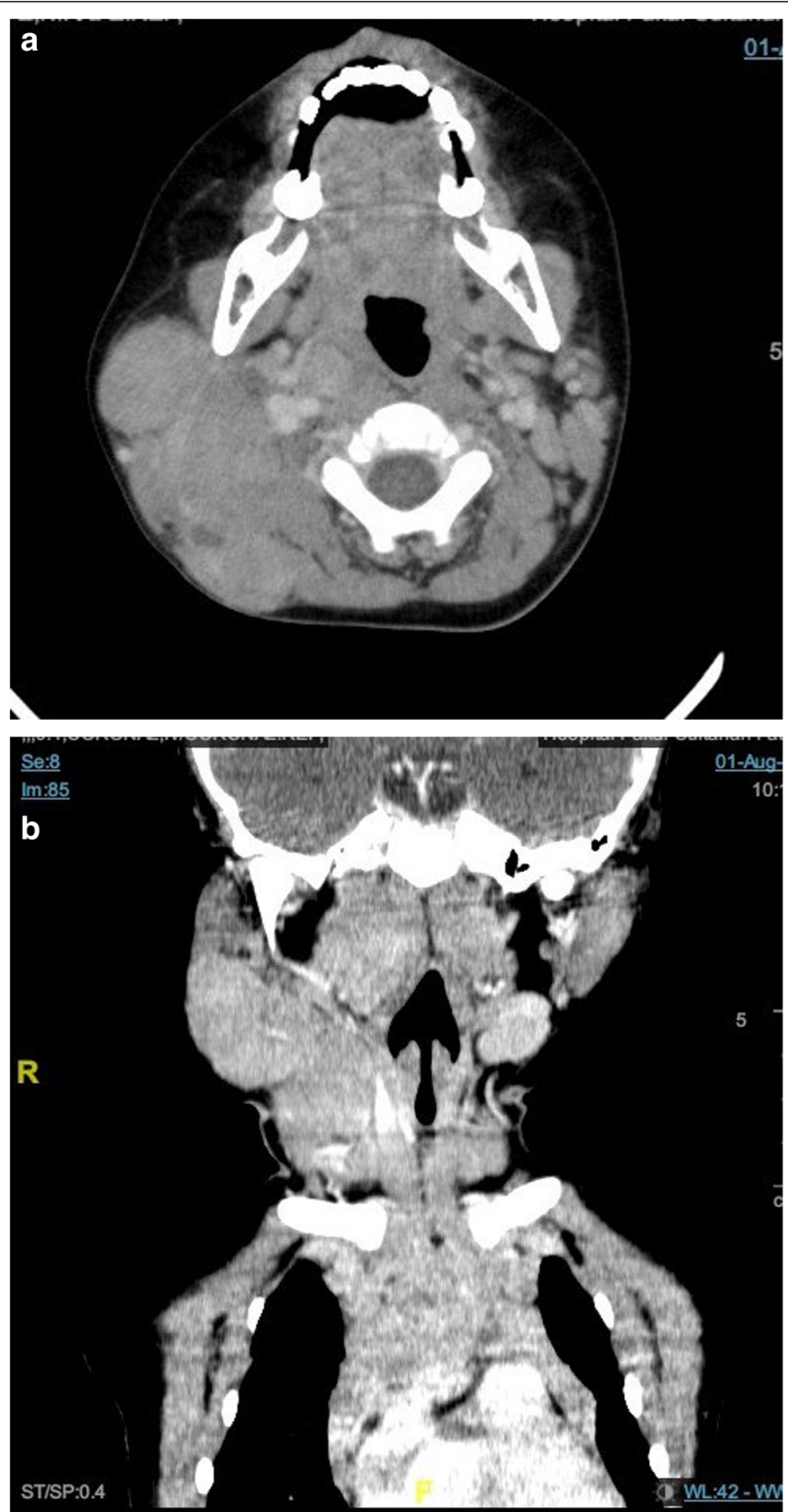

Fig. 2 a, b: multiple large lobulated LN seen in the bilateral cervical region more on the right side, predominantly involving level II,IIIIV,V (white arrow) b: Right parapharyngeal space effaced, enlarged right retropharyngeal nodes causing mild effacement of the right nasopharynx and oropharynx

\section{Discussion}

Histiocytic disorders are a family of diseases that occur when there is an overproduction of leucocytes known as histiocytes that can lead to neoplastic formation [2]. A revised classification by The American Society of Hematology in 2016 grouped the disease into five, namely 

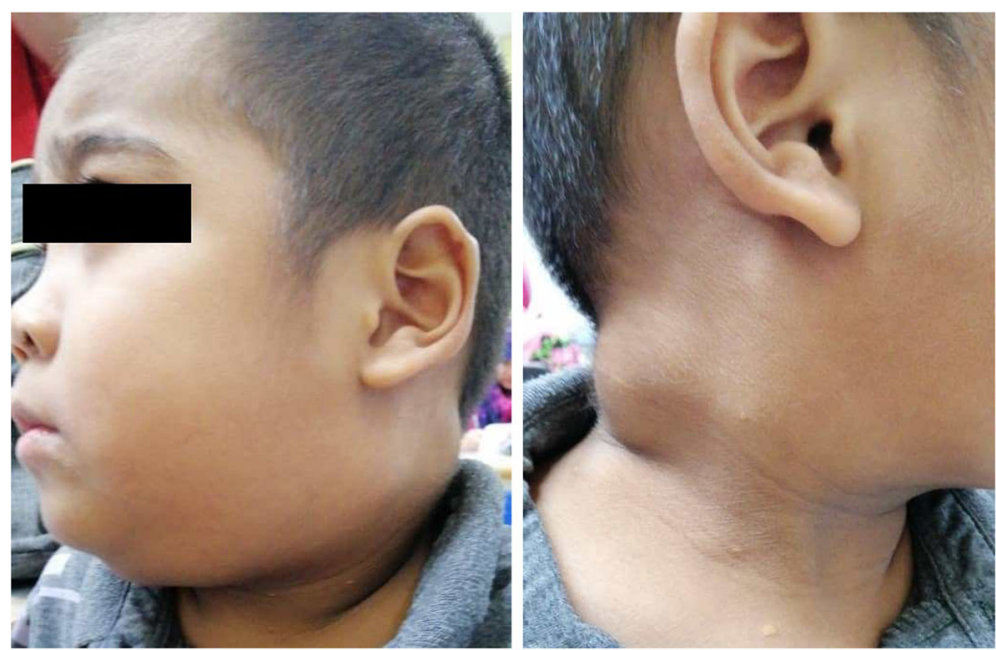

Fig. 3 a (left), b (right): Shows reduction in size at 6 months follow up

Langerhans-related, cutaneous and mucocutaneous, malignant histiocytoses, Rosai-Dorfman disease (RDD), and hemophagocytic lymphohistiocytosis and macrophage activation [3].

Langerhans cell histiocytosis was introduced as a collective designation for a spectrum of clinicopathologic disorders characterized by proliferation of histiocyte such as cells accompanied by eosinophils, lymphocytes, plasma cells, and multinucleated giant cells. The destructive histiocytes are Langerhans cells and dendritic mononuclear cells normally found in the epidermis, mucosa, lymph nodes, and bone marrow [4].

The symptoms of types of histiocytoses are similar. The subtype of disease is often misdiagnosed. Cervical lymph node enlargement is frequently accompanied by fever and increased inflammatory markers which are non-specific signs of infection or inflammation. In our cases, histiocytoses are likely to be mistaken for lymphoma due to its typical presentation of painless cervical lymphadenopathy accompanied by nonspecific signs of immune activation such as fever, neutrophilia, and elevated C-reactive protein. Therefore, RDD and LCH should be considered in the differential diagnosis of painless, unilateral, and bilateral lymphadenopathy.

The diagnosis of histiocytosis is based on history and physical examination and confirmed by histopathology examination. Specimens can be attained by FNA or surgical biopsy. The former is considered a sensitive and unswerving method to be carried out as an outpatient procedure [5].

In RDD, surgically excised lymph nodes are yellowwhite with frequent capsular and pericapsular fibrosis. Typically, the lymph node sinuses are expanded by a proliferation of distinctive histiocytes exhibiting enlarged round or oval vesicular nuclei with welldefined, delicate nuclear membranes and a single prominent nucleolus. The hallmark of the SHML histiocyte is the presence within the cytoplasm of variable numbers of intact lymphocytes, a phenomenon referred to as lymphophagocytosis or emperipolesis, defined as lymphocytic penetration of and movement within another cell, in this case, the histiocyte [6]. Shi et al. [7] concluded 3 out of 25 cases (12\%) in nodal aspirations were misdiagnosed or inconclusive. Misdiagnosis in RDD is less frequent in nodal presentation in comparison to extra nodal which is 6 out of $12(50 \%)$.

The histopathological pattern in $\mathrm{LCH}$ demonstrates a diffuse infiltration of large pale staining mononuclear cells that resemble histiocytes with twisted or grooved vesicular nuclei. The eosinophils vary and typically interspersed among the histiocytes along with the presence of plasma cells, lymphocytes, and multinucleated giant cells in the background. The histopathology is similar in all LCH variants except in acute disseminated form as they also demonstrate acute form of lymphomas. The presence of Langerhans cells is necessary for diagnosis, which requires additional diagnostic methods [8]. Immunohistochemistry testing in $\mathrm{LCH}$ is positive for S-100 and anti-CD-1a, same as presented in case 1 . $\mathrm{LCH}$ is characterized by antigen Ki-67 that selectively binds to a nuclear antigen which is only expressed by proliferating cells [9].

Due to low incidence, no treatment protocol has been defined for RDD. The self-limiting nature of the disease makes intervention unnecessary except in airway cases [5]. "In a review of literature, $50 \%$ of patients with RDD 
require no treatment and $82 \%$ of untreated patients experience spontaneous remission."

While some patients with $\mathrm{LCH}$ do not require treatment, some with more extensive disease needs chemotherapy. A comprehensive team comprised of hematologist and oncologists are crucial in the management of LCH. Most patients will survive the disease. $\mathrm{LCH}$ in lymph node consider "low risk." Patients with $\mathrm{LCH}$ require long-term follow-up to detect late complications of disease which includes involvement of liver, lung, skeletal deformity.

\section{Conclusion}

Finally, both RDD and LCH are histiocytic proliferative disorder that can be encountered in nodal and extranodal locations. Recognizing these diseases is vital to avoid misinterpretation and subsequent unnecessary treatment. Meticulous interpretation of FNAC and biopsy slides along with immunohistochemistry would benefit in early diagnosis and prompt management.

\section{Abbreviations}

LCH: Langerhans cell histiocytosis; SMHL: Sinus histiocytosis and massive lymphadenopathy; FNAC: Fine needle aspiration cytology; CT: Computed tomography; FNA: Fine needle aspiration; RDD: Rosai-Dorfman disease

\section{Acknowledgements}

Not applicable.

\section{Authors' contributions}

All authors have read and approved the manuscript and ensure that this is the case submitted for publication. IA, HG, SH and KN done the concepts and definition of intellectual content. While IA and HG done design and Manuscript editing. IA and KN done the Literature search, Data acquisition and Data analysis. IA, HG, and KN done the Manuscript preparation. $\mathrm{HG}$ and $\mathrm{SH}$ done the Manuscript review. $\mathrm{SH}$ is the Guarantor.

\section{Funding}

No funding need for analysis of data.

Availability of data and materials

Not applicable.

Ethics approval and consent to participate

Not applicable.

\section{Consent for publication}

Written consent from parents was obtained.

\section{Competing interests}

The authors declare that they have no competing interests.

\section{Author details}

${ }^{1}$ Department of Otorhinolaryngology, UKM Medical Centre, Jalan Yaacob Latiff, Bandar Tun Razak, 56000 Cheras, Kuala Lumpur, Malaysia. ${ }^{2}$ Faculty of Medicine, Universiti Kebangsaan Malaysia, Kuala Lumpur, Malaysia.

${ }^{3}$ Otorhinolaryngology Unit, Department of Surgery, Faculty of Medicine and Health Sciences, Universiti Putra Malaysia, 43000 Seri Kembangan, Selangor, Malaysia.
Received: 3 June 2020 Accepted: 25 August 2020

Published online: 03 December 2020

References

1. Jackson MA, Long S, Prober C, Fischer M. Principles and practice of pediatric infectious diseases, 5th edn. Chapter 12. 2018. p. 102

2. Histiocytic disorders, Histiocytosis Association Incorporated; info@histio.org, https://www.histio.org/page.aspx?pid=378\#.XzJcEygzY2w

3. Emile JF, Abla O, Fraitag S, Horne A (2016) Revised classification of histiocytoses and neoplasms of the macrophage-dendritic cell lineages. Histiocyte Society; Blood. 127(22):2672-81

4. Kumar YP, Agrawal J, Mohanlakshmi J, Kumar PS (2015) Langerhans cell histiocytosis revisited: case report with review. Contemp Clin Dent. 6(3):432436. https://doi.org/10.4103/0976-237X.161912

5. Lima, Felipe Barbosa et al. "Rosai-Dorfman disease with spontaneous resolution: case report of a child." Revista brasileira de hematologia e hemoterapia vol. 33,4 (2011): 312-4. https://doi.org/10.5581/1516-8484 20110083

6. Foucar E, Rosai J, Dorfman R (1990) Sinus histiocytosis with massive lymphadenopathy (Rosai-Dorfman disease): review of the entity. Semin Diagn Pathol. 7:19-73

7. Shi Y, Griffin AC, Zhang PJL, Palmer JN, Gupta P (2011) Sinus histiocytosis with massive lymphadenopathy (Rosai-Dorfman Disease): a case report and review of 49 cases with fine needle aspiration cytology. Cytojournal 8:3. https://doi.org/10.4103/1742-6413.76731

8. Neville BW, Damm DD, Allen CM, Bouquot JE. Oral and maxillofacial pathology. Ch. 13. Vol. 2. New Delhi: Reed Elsevier India Pvt. Ltd; 2004. Langerhans cell histiocytosis; Hematological disorders; pp. 513-4.

9. Bartnick A, Friedrich RE, Roeser K, Schmelzle R. Oral Langerhans cell histiocytosis. Vol. 30, Issue 2, April 2002, Pages 91-96 J Craniomaxillofac Surg 2002;30:91-96.

\section{Publisher's Note}

Springer Nature remains neutral with regard to jurisdictional claims in published maps and institutional affiliations.

\section{Submit your manuscript to a SpringerOpen ${ }^{\circ}$ journal and benefit from:}

- Convenient online submission

- Rigorous peer review

- Open access: articles freely available online

High visibility within the field

- Retaining the copyright to your article

Submit your next manuscript at $>$ springeropen.com 